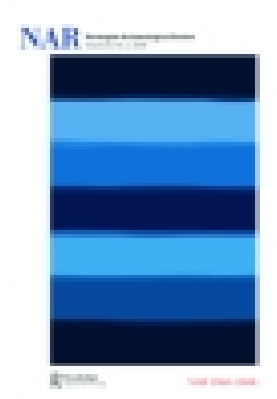

Norwegian Archaeological Review

ISSN: 0029-3652 (Print) 1502-7678 (Online) Journal homepage: http://www.tandfonline.com/loi/sarc20

\title{
Palimpsests of Immaterial Assemblages Taken out of Context: Tracing Pompeians from the Void into the Digital
}

\section{Paul Reilly}

To cite this article: Paul Reilly (2015): Palimpsests of Immaterial Assemblages Taken out of Context: Tracing Pompeians from the Void into the Digital, Norwegian Archaeological Review, DOI: $10.1080 / 00293652.2015 .1086812$

To link to this article: http://dx.doi.org/10.1080/00293652.2015.1086812

Published online: 12 Oct 2015.

Submit your article to this journal $[\pi$

Џll Article views: 24

Q View related articles $\longleftarrow$

View Crossmark data \lceil 


\title{
Palimpsests of Immaterial Assemblages Taken out of Context: Tracing Pompeians from the Void into the Digital
}

\author{
Paul Reilly
}

\begin{abstract}
This paper explores some ontological aspects of archaeological voids and enclosures together with their translations and substitutions, and considers the nature of spaces within material archaeological deposits and artefacts. The dematerialized and rematerialized bodies of the victims of Vesuvius in CE 79 are reappraised as a case study. By problematizing the voids we are able to think critically about the ontological status of the victims' persistent traces and residues. Specifically, using Gavin Lucas' grid of forces models, we explore how these traces and residues have been transformed into different kinds of objects, including, most recently, rematerializations in the digital, through their ongoing intra-actions within the domains of archaeology, museology, and additive manufacturing. Through this analysis the ambivalent nature of these traces and residues becomes more sensible.
\end{abstract}

'There is no erasure finally. The trace of all reconfigurings are written into the enfolded materialisations of what was/ is/ to-come' (Barad 2010, p. 264).

\section{INTRODUCTION}

Surfaces, interfaces, and unconformities have a special status in the archaeological record. Marking boundaries and delineating transitions, they also present a unique aesthetic peculiar to the trenches. Archaeologists like to survey, photograph, and draw them prior to making a new, hopefully equally pleasing or intriguing, surface when they have finished excavating, that is dematerializing, the context or feature. The contexts themselves, however, are more complex and draw attention to the concept of boundedness; inside and outside. Boundedness poses some problems to conventional understandings about the nature of the archaeological record in the case of the excavated material being composed of immaterial, interior spaces or enclosures (e.g. Ingold 2007). As Severin Fowles observes, 'packed between the multitude of self-evident things, are crowds of nonthings, negative spaces, lost or forsaken objects, voids or gaps - absences in other words, that also stand before us as entitylike presences with which we must contend' (Fowles 2010, p. 25).

Sometimes a bounded space denotes the interior of a place, such as a hypogeum, catacomb, or mine, or the worked inside of a hollow artefact like, for instance, a bulla, a Neolithic and Bronze Age Sumerian accountancy technology in which clay tokens were sealed within clay envelopes. Juxtaposed to

Paul Reilly, Department of Archaeology, Faculty of Humanities, University of Southampton, Southampton, UK.

E-mail: p.reilly@soton.ac.uk 
these products of human agency are negative spaces, or voids, the results of natural agency, delimiting exterior boundaries of a dematerialization. Although immaterial they sometimes persist as a profoundly intransigent absence-presence or, as Sibel Horada puts it, a 'polyvalent lacuna' (Horada 2014). The cavities left by the unfortunate witnesses to, and victims of, the cataclysmic end of the Roman town of Pompeii are a classic example.

This paper aims to explore some ontological aspects of archaeological voids and enclosures together with their translations and substitutions, and considers the nature of spaces within material archaeological deposits and objects. The dematerialized and rematerialized bodies of the victims of Vesuvius in CE 79 are reappraised as a case study. By problematizing the voids, we are able to think critically about the ontological status of the victims' persistent traces and residues. ${ }^{1}$

I start by describing the circumstances that led to the creation of this enigmatic assemblage of victim traces and residues, and provide an account of their subsequent reiterations in different media to the present time. Next, I develop Gavin Lucas' 'grid of forces' ontological framework for defining objects and events in order to gain insights into the changing nature of the various instantiations of the victims of Vesuvius in this extending assemblage. Specifically, I explore how these victim traces and residues have been transformed into many different kinds of objects, each with their own biographies, to create a fluid assemblage of shifting meanings that extends from the volcano's deadly eruption through the present and into the future. I draw attention to the sometimes slightly, and at other times radically, different rematerializations that emerge as we and our constantly changing apparatus, techniques, methods, tools, and theoretical assumptions intra-act ${ }^{2}$ with one another, particularly as they become entangled with the digital, within the domains of archaeology, museology, and additive manufacturing. Through this analysis the ambivalent nature of these traces and residues becomes more 'sensible'. Some ethical issues are also raised concerning the treatment, trade, and display of these remains of human beings.

\section{SUSPENDED MOMENTS}

The victims of Vesuvius have been subject to several centuries of near continuous investigation, appraisal, and wonder. This extended engagement at Pompeii presents us with an opportunity to reflect on the ontological multiplicity of a multifaceted, 'dynamic assemblage' (see Fowler 2013).

For some these human ${ }^{3}$ forms-cum-voids - bodies lacking almost any corporeal remains - are more or less empty moulds. For others, they are full of human existence, reservoirs brimming with mortal despair, the embodiments of an ancient 'other' (Dwyer 2011, p. 51). They represent a synchronic cross-section of the final moments of people who succumbed to the pyroclastic surges, and were then immured in the ashes of Vesuvius towards the end of CE 79. A sequence of six distinct pyroclastic surges has been identified from the CE 79 eruption of Vesuvius. The fourth surge is implicated with most of the fatalities in Pompeii (Mastrolorenzo et al. 2010, p. 4).

The victims of this eruption died instantaneously, in 'mid action', due to thermal shock (Petrone et al. 2014). Nevertheless, traces of them persist, residual memories recalling their 'life-like' poses captured at the second when the torque of life was replaced by the torque of death due to cadaveric spasm: 'a rare but diagnostic form of instantaneous muscular stiffening associated with instant violent death' (Mastrolenzo et al. 2010). Excavations at Pompeii since the 18 th century have combined to produce a unique and extraordinary assemblage of victim traces and residues, some immaterial, others not (or, at least, not yet). 
In the case of this assemblage of Pompeian victims, at least four threads of residual memory stubbornly persist. Each imprint of the corpses buried by the fine ash does not only encapsulate fine morphological details, recalling the victim's features, clothes, hairstyle, musculature, and pose (for a detailed discussion of their forms see Dwyer 2005, 2010, 2011), but also inside the identical geometrical envelope is a residual absence, presenced by a void. Residues of the victim's skeleton can also be present, perhaps even articulated (Lazer 2009), the voids thus creating a unique ossuary. In addition, some victims were wearing, or carrying, possessions, such as bracelets, when they perished. These and other artefacts have been recovered in situ.

However, it is the voids that remain the most enigmatic element in the assemblage. What are these hollow, human-shaped forms? Contradictory and anomalous theoretical possibilities abound and some may coexist. Examples include mimetic casts (see Feldman 2006), khoratic receptacles (see Domanska 2005), interobjective indexical signs of a hyperobject (see Morton 2013), hauntological (im)possibilities (see Barad 2010), and residual memories (Lucas 2012). Their status has profound ethical implications to their subsequent treatment (see also Feldman 2006, Ouzman 2006, Lazer 2009, pp. 269-270). I will return to some of these possibilities later.

Ontologically ambiguous, conceptually not structure, artefact, ecofact, or deposit, and sitting on the cusp of being either (or neither) positive or negative stratigraphic features, they are, nonetheless, sealed contexts. Stratigraphically, this (im) material ${ }^{4}$ assemblage is also simultaneously earlier, co-terminus, and later than the volcanic spew. These residues and traces are, in fact, palimpsests encapsulating 'the dual process of inscription and erasure' (Lucas 2012, p. 115), demanding ontological inspection. How autonomous are they? Are these voids actually the final resting places of the victims of Pompeii? Eugene Dwyer is by no means alone in sensing the eschatological ellipsis implied in the title of his book: Pompeii's Living Statues: Ancient Roman Lives Stolen from Death (Dwyer 2010).

\section{SUSPENDED MOMENTS IN NEW CONTEXTS}

The first archaeological encounter with the negative forms found at Pompeii occurred in 1772 in the Villa of Diomedes, during which only the ash imprints of parts of a woman's body were salvaged (Lazer 2009, p. 247). It was not until the mid-19th century that the first successful experiments to capture the shapes of the voids using plaster of Paris produced some positive forms of furniture and a door. The first casts presenting the visages of human victims of the cataclysm were made in 1863 (Lazer 2009, p. 247) and were an immediate sensation. The imprints and voids in the ash, however, began to withdraw, almost unobserved, into the background.

What becomes of the original, anthropomorphic cavities when archaeologists - such as Guiseppe Fiorelli in the 1860s, or Amedeo Chicchitti in the 1980s - puncture their ancient, hardened volcanic shells only to interrupt the 'act of discovery' (see Edgeworth 2003) by injecting them with modern liquid plaster, or waxes and resins, to beget uncanny fetish-like pseudomorphs? Clearly, the archaeological encounter excavator's experience from now on will be radically altered, requiring virtually a gestalt shift in their perception, due to this most invasive post-depositional process, this 'transgression' (Shanks 1992, p. 69) to the sealed context of the victim.

Soon after their production, the earliest casts - the quality of which tended to be somewhat hit-and-miss - were removed from their places of discovery to protect them from the elements. They were first installed in a rather grim-sounding building known as the 'House of the Cadavers of Gesso'. In 1875, however, they were removed 
to a new, and better-illuminated, museum and exhibited in vitrines. With this change of context the meaning of assemblage could also be recast. Now the assemblage was transformed into a curatorial project aimed at producing performable events, namely exhibitions. By this time, the casting process has largely been perfected and the collection had grown (Dwyer 2010).

By the 1880s individual casts had become favourites with commercial engravers and photographers, establishing yet another biographical thread witnessing another event, another transformation: the victims' rematerialized into albums, post cards, and other publications. Previously, artefacts of scientific documentation in the 1860s (although they show evidence of restitution), the casts of the 1870s and 1880s were retouched in an apparently stylized manner to reflect contemporary aesthetics and thereby effect 'a new canon of showpieces: the archaeological artefacts as works of art' (Dwyer 2005).

However, by the time of a crammed exhibition in 1889, the floruit of the individual, celebrated cast had waxed and waned at Pompeii itself, where the importance of showing groups of casts in the context of their find spot asserted itself (Lazer 2009, pp. 257-258). According to Dwyer (2005), after the on-site museum had been filled to capacity in the 1890 s, 'it again became necessary to re-evaluate the nature of the casts, and they once again became archaeological artefacts'. Internationally, however, their iconic status continued to expand. This celebrity was underscored when Fiorelli gifted a collection of half-scale terracotta reproductions ('reductions') of the earliest successfully executed casts to the German Kaiser Wilhelm II in 1888. This collection was given a permanent exhibition in Berlin's Altesmuseum (Dwyer 2005) but it is now 'lost' (Dwyer 2011, p. 54).

In 1984, voids and residues representing some 55 victims were encountered at Oplontis, near Pompeii. One cavity was selected to trial a variation of the lost-wax casting technique. Molten wax was poured into the chosen cavity and allowed to set. The wax form uncovered was then encased in a plaster matrix, after which the wax was replaced by epoxy resin. Ten years later this unique, transparent, epoxy pseudomorph, encapsulating both skeletal remains and artifacts, formed part of an exhibition that travelled to Australia. In Sydney, Estrelle Lazer was permitted to investigate this assemblage of the so-called Lady from Oplontis using conventional x-ray and CT scanning technology (see Lazer 2009, pp. 260-264).

New materials and technologies continue to be entangled with the traces and residues of the victims of Vesuvius. For example, in 1991, Allan McCollum exhibited an installation entitled The Dog from Pompeii August 24, $79 A . D$., in which several dozen recasts of the second-generation plaster-cast known as the Dog in Chains were executed in reinforced fibreglass (see McCollum n.d.). A decade on, another American artist, Gary Staab, was commissioned to make models of four original casts for the 2011 Vesuvius Strikes Again exhibition held in New York. According to Jared Lobell, Staab's commission created a new type of evidence, as his work recorded 'the context in which the original casts were fashioned' (Lobell 2011). Photogrammetry was employed to produce a computer-generated 3D model, which was, in turn, fed into a computer-controlled milling process which captured the overall geometry - but not the subtle details of the surface morphology - of the original casts in their setting by cutting into a block of highdensity foam. Each foam model was then coated in a thin layer of plaster and the missing fine details were sculpted in. The final pieces were saturated in industrial strength epoxy resin for durability and painted before shipping to the exhibition.

To this day casts representing the victims of Vesuvius continue to figure prominently in exhibitions (e.g. Fig. 1) and draw huge audiences in the great museums and galleries of the world (e.g. Roberts 2013). Casts of the victims 


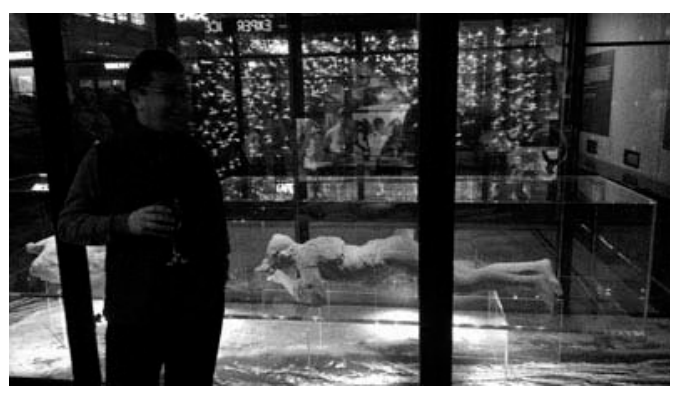

Fig. 1. Pompeian victim cast of a cast (effigy) at TAG2014 Conference Reception held at Manchester Museum (Photo Catriona Cooper).

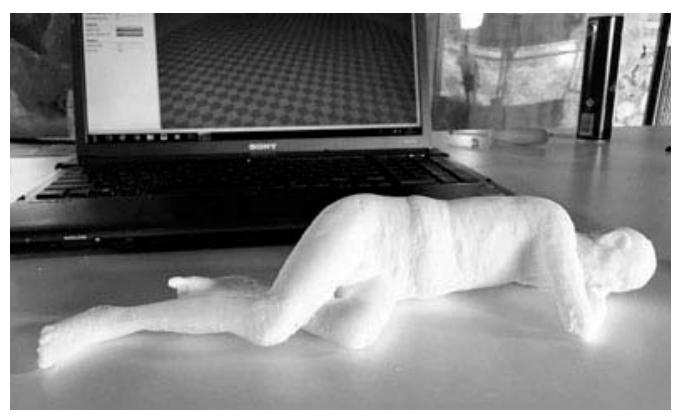

Fig. 2. 3D-printed instantiation of a Pompeian victim (Photo reproduced courtesy of Delta Wasp).

of Vesuvius remain highly sought after within the global memory market. However, the originals are fragile. To satisfy this ongoing demand, newer, more sophisticated technologies are being introduced into this extending assemblage. For example, in 2015, the Special Superintendence for Cultural Heritage of Pompeii, Ercolano, and Scabia is working with an Italian company called WASP to manufacture full-sized and scaled 3D prints of a number of the original casts (as shown in Fig. 2, for example (Nath 2015)).

\section{POLYVALENT ASSEMBLAGES AND RELATIONAL CONTEXTS}

Gavin Lucas, building on Laurent Olivier (2004), argues that imprints, such as the 3.6 million-year-old footprints of hominids encountered at Laetoli in Tanzania, are not simply 'signs of' an event, they are residual physical memories, the 'extended ripples' of an object, assemblage, or event along a 'continuum on which the past is stretched into the present' and out into the future (Lucas 2012, p. 208). Timothy Morton describes this link between fossil prints and the modern viewer as 'some shared sensual space'; a sensuous connection that is mediated 'interobjectively' between the realities of the hominid, the prints, the rock, and ourselves, despite their vastly differing timescales (Morton 2013, p. 86). For Lucas, the fundamental property that helps preserve these residual memories across different assemblages is that of 'irreversibility'; that is, changes to materials which cannot be easily reversed. Put more prosaically, some things last longer than others. Lucas uses the example of combining clay, water, and fire to produce ceramics. In so doing, an 'irreversible change, has occurred which, even after breakage retains traces of this materialization' (Lucas 2012, p. 213). Equally important for preserving these residual physical memories is the absence of dematerializing forces, which would otherwise threaten the integrity of the assemblage (Lucas 2012, p. 214).

However, lying buried for so long undisturbed, and relatively stable in their volcanic cocoon, we should recognize that the traces and residues that survive into the present do not subsist in the immediacy of a teleological process. They are not the ultimate, or final, traces or residues. The 'archaeological record' is what the philosopher Alfred Whitehead referred to as 'an incompletion in the process of production' (Whitehead 1929, p. 298). The term 'archaeological record' has many possible meanings, but, as Lucas (2012) shows, they may usefully be condensed down to just three: the first connotation is that of material culture, materiality, or artefacts understood in their broadest sense; the next meaning is expressed in terms of how deposits and assemblages come to be, something he labels as 'formation theory'; 
finally there is the archaeological record as constructed in the present, also known as the archive. Lucas contends that all three aspects of the archaeological record need to be considered as an imbricated whole, because viewing any one facet in isolation can lead to fundamental disconnects or an interpretive dilemma, in which explanations often hover between vacuity and incommensurability' (Lucas 2012, p. 169).

Lucas seeks an alternative to this fragmentation of approaches by offering a new agenda of mutually constituting archaeological 'interventions' and 'entities'. In this account, the practices of the field archaeologist are not so much data collection but interventions, or material interactions, in which tools and procedures are mobilized locally to materialize new entities or artefacts (e.g. drawings, samples, photographs, context sheets, field diaries, finds); it is these new, mobile, dynamic assemblages of autonomous objects that become archives. Lucas builds on Manuel DeLanda's assemblage theory (which draws on the philosophy of Giles Deleuze and Felix Guattari) to rethink and deepen the concept of the 'archaeological assemblage' whilst still successfully encapsulating the interplay of its two traditional affinities of deposition and typology. In this reworking, assemblages are articulated in terms of external relationships, such as their relations to their environment and other assemblages, as opposed to the internal configurations of their component parts, which are recognized as having a certain amount of autonomy, insofar as they can move between assemblages and recombine elsewhere in other spatiotemporal contexts. Indeed, '[a] lmost all, if not all, objects are strictly speaking residues of prior assemblages' (Lucas 2012, p. 204).

Central to Lucas' account of how an archaeological site is translated into an archive as the result of archaeological interventions are processes of materialization and dematerialization, 'in which objects and people are made and unmade, in which they have no stable essences but are contextually and historically contingent (Lucas 2012, p. 166). Materialization, or inscription, is characterized as a stabilizing force of assembly, one that pulls things together and organizes them. Here, depositional processes (called 'containment' or 'territorialization') cohere to assemble, or gather, things in specific places. Complimentary processes (called 'enchainment' or 'coding') cohere to generate recurring associations such as typological similarities or repeated find combinations. The symmetrical opposite of materialization is dematerialization, a destabilizing, disassembling, or erasing force characterized by the dual processes of 'exposure' (or 'deterritorialization') and 'dispersal'. This entropic force pulls apart, separates, and displaces materials and artefacts from their original setting. These two forces are always in tension, one side fostering aggregation, persistence, and continuity, the other producing gaps, absences, and discontinuities. It is this conception of materialization that enables Lucas 'to conjoin what was previously separate: the ontology of things (i.e. materiality) and their biographies (formation theory)' and to argue that 'the material world is, at any given time, an archive of this process of (de) materialization' (Lucas 2012, p. 205).

Against this background, Lucas developed a 'flat ontology' in which both objects or assemblages equally exist within a grid of materializing and dematerializing forces, 'defined by qualities of permeability and persistence' (Lucas 2012, pp. 187-188), and processes of 'enchainment and containment' (Lucas 2012, pp. 210-214). Mapping the various instantiations of Pompeian victims onto these powerful conceptual frameworks, we begin to register the polyvalent character of this dynamic assemblage. Most importantly, we discern quite clearly how the meaning and nature of these instantiations changes with context, and how, in particular, certain interventions, or events, cause parts of the assemblage to experience rapid changes in their ontic status. I will explore the assemblage first through the framework of 
Lucas' grid of forces defining the qualities of objects. I will then consider his grid of forces defining the processes of assembly and disassembly.

Lucas frames his first grid of forces as follows: 'One might think of [objects] as ideal points on a grid defined by the qualities of permeability and persistence -that is, how impermeable they are to material reconfiguration on the one hand, and how enduring they are on the other' (Lucas 2012, p. 187). I characterize the four forces operating in his un-calibrated, nonlinear model as fleeting, unfolding, enduring, and seeping (Fig. 3). This classification is relational. Fleeting and unfolding residues are characterized by their transient existence before they disappear from the record. Differentiated by their relative impermeableness their separation is merely one of degree. Lucas positions exemplary objects within each force in his grid. 'Vegetable stew', for instance, can be regarded as a quite permeable material, with a short use-life, compared to a 'leather shoe', which tends to last longer and is more impermeable. By contrast, both enduring and seeping traces and residues persist for considerably longer spans, perhaps millennia. A 'pottery vessel', for example, is very impermeable and will endure for ages, albeit in the form of stubbornly persistent sherds. Likewise, a 'church' may stand for centuries, but parts seep out of the building as it is worn or damaged and seep in when repairs and alterations are made. In other words, the building remains a stable residue through a sedimentation process in which substitutions to its material matrix are enfolded within its persistent conformation.

How does the extended assemblage emerging from the traces and residues of victims of the fourth surge fit into this analytical framework? Figure 3 is one possible mapping. At the outset, I should stress that placing the various traces and residues of these victims within this framework as coordinates gives a misleadingly static impression. The arrows try to indicate trajectories to unsettle such a line of interpretation, since any notion of fixity here is misplaced, as numerous

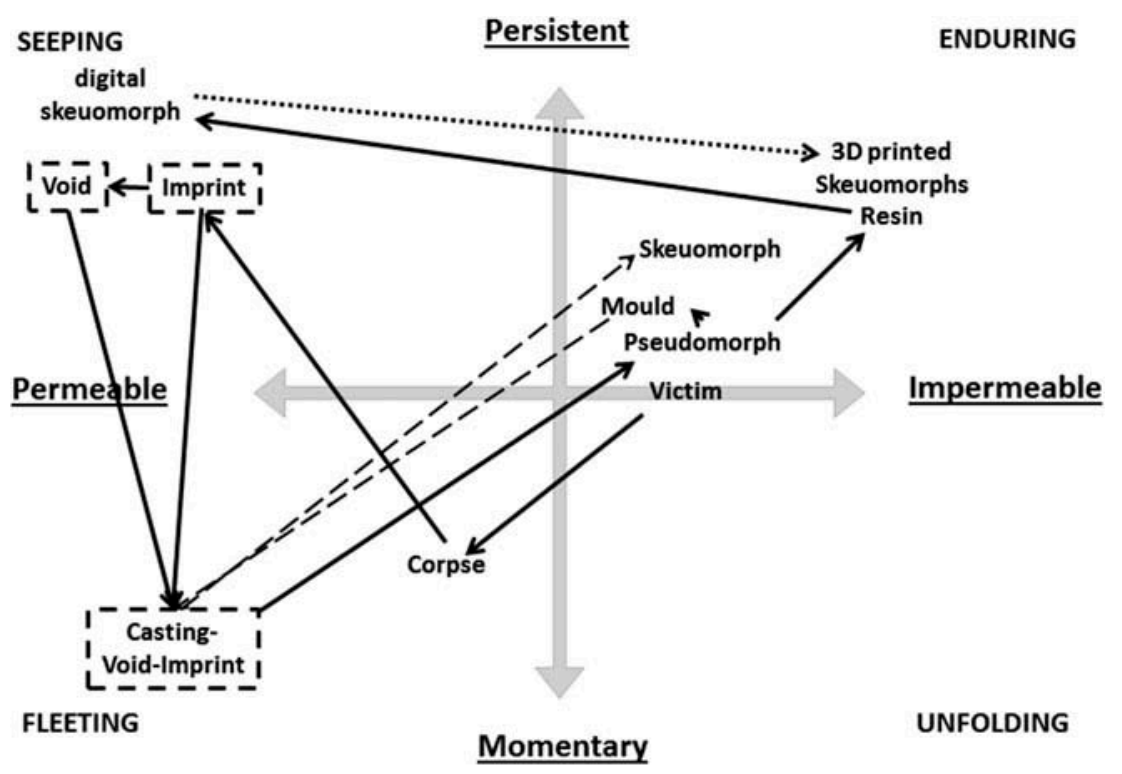

Fig. 3. Mapping the extended Pompeian assemblage due to the fourth pyroclastic surge to the 'persistency versus permeability' grid of forces framework (after Lucas 2012, Fig. 12, p. 187, quadrant labels added). 
ontological possibilities can be associated with this assemblage. As Yvonne Marshall and Ben Alberti (2014, p. 34) write, '[n]either an object nor an assemblage is ever a fixed, singular entity. Each instantiation is unique, special and particular', although we must also recognize that the degree of differentiation can be slight as well as substantial.

In life, the victims of Vesuvius had relatively permeable bodies and could have expected the bracketed life-spans typically accorded to mortals. They could also rove about the town and its hinterland, and beyond, fairly unimpeded. Their lives then were unfolding when they were cut short by the fourth surge. Once dead, instead of the mortuary rites they could normally have expected, a layer of volcanic material engulfed the victim's body and hardened to form a long-lasting, but porous, cocoon-like tomb. The decomposing corpses seemingly seeping into surrounding permeable deposits eventually left both the imprints and the voids. These stable, symbiotic, (im)material pairings persisted for nearly 2000 years, until archaeologists introduced liquid plaster into their context.

Each instantiation of a victim due to the casting process precipitates a glitch in these residual memories; a glitch which manifests as a brief flicker (at least in archaeological measures of time) between a disappearing and reappearing absence-presence. The first glitch occurs when the previously ethereal, but stable, black, ghost-like, and 'naturally' produced absence-presence, contained within its volcanic tomb, is violated by this physical alterity. The void 'disappears' as the liquid plaster is injected. A chain of events is triggered by the instantiation (or (re)materialization) of the victim as an opaque, white figure, which is also, in fact, a modern pseudomorph, literally a false body. Pseudomorphs are produced in situ through a process of substitution in which the body's shape remains constant but the properties of the replacement material are completely different from the original. In this context, however, they are most commonly referred to as 'casts'. In many instances, however, surviving skeletal remains were also incorporated into the fabric of the cast, in which case the newly created object can also be considered as both a reliquary and a fetish.

Second-generation casts were formed using moulds taken from a pseudomorphcum-reliquary. Echoes of the act of discovery resonate within the moulds' negative spaces as each successive casting produces another flicker, another glitch. At one more step removed, no trace of the victim's skeleton could be transferred into these latest derivatives, which now become effigies. Additionally, as these effigies are reproduced in new and different materials, with material affordances far removed from their ultimately organic prototypes, they are also technically skeuomorphs; that is, the form of the object is made in another material or by other techniques.

Although they will not be pursued here, significant questions also burnish the auratic qualities of these enduring enigmatic objects; in other words, those qualities that make us feel connected to the past emotionally as well as intellectually. It is impossible to ignore the ineffable aura that still makes some of these casts so iconic. This aura, it should be noted, seems to migrate into the subsequent second- and later-generation rematerializations, known as 'replica casts', which feature in many museum exhibits around the globe (e.g. Fig. 2) ${ }^{5}$. Many people display a strong visceral reaction when confronted with these casts (e.g. Lazer 2009, p. 251, Dwyer 2011, pp. 51-54). For instance, the writer and statesman Luigi Settembrini recounts his awe and emotion provoked on seeing the casts in a letter, published in the Giornale di Napoli on February 17, 1863: 'but you, oh my Fiorelli, have uncovered human suffering and whoever has an ounce of humanity will feel it' (cited in Roberts 2013, p. 297). 


\section{SOME ONTOLOGICAL CONSIDERATIONS}

What is the ontological status of these casts, considered by some to be 'paradigmatic in the documentation of perishable remains' (see Dwyer 2011, p. 56) permitting further forensic examination? Are they casts of the interior surfaces of the enclosure or casts of the voids? Are archaeologists simply taking a cast of the form of the victim created after the ash engulfed the body or is this propinquity more complex? Is the memory invoked by the absence more present than we might ordinarily assume? Eva Domanska, in her fertile archae-ontological analysis of the Argentinian desaparcido, situates the absent bodies of the disappeared in the conceptual space of a 'non-absent past', characterized as being 'the ambivalent and liminal space of "the uncanny", an 'awesome "empty grave", occupied by 'ghostly artifacts'. This empty grave 'not only occupies a particular place, but itself is a place and forms a place', a form of receptacle, or khôra, 'an active dynamic place endowed with potentiality', perhaps a 'place where death finds shelter' (Domanska 2005, pp. 405-406). This prompts a question in the context of the Pompeian traces: as the voids are filled by material, is the absence suffused by the injected substance, or, in this rather fleeting moment, is that absence infused into the solidifying cast to become something more physical and enduring? In other words, are these immaterial contexts obliterated by the injected substances used to obtain the casts or is the immaterial instantiation still co-present in the cast? Later, when the cast is exhumed, is the void 'restored', is some aspect of the missing person, or the lost body, repatriated, and is the context reinstated?

Another chain of events can also be implicated in the negative spaces. If the casts had never been made, and the volcanic cocoon and the imprint simply picked and shovelled away, would the absence still be there occupying the same, original space, but now unbounded, undetectable, and unappropriated? Would it escape or dissipate when its cocoon was breached? I would argue that the spaces in which the Pompeian victims of the fourth pyroclastic surge both lived and died endure. As the plaster dries, the pseudomorph shrinks away from the imprint. The absence resurges, at least for a little while, in the space which reappears as the boundaries demarcating the domains of exterior and interior are reconfigured. If so, yet another paradox raises its ironic head. 'Excavation' in the context of these enclosures-cum-voids is non-invasive, at least until 'the dig' ends. Does this mean that when these trenches are backfilled that the 'original' contexts, assemblages, and palimpsests - these ghost-like residual memories - are finally erased, and inscribed anew?

Lucas' second tool for analysing assemblages is called the 'grid of forces of assembly and disassembly'. Within this framework he puts the focus of attention firmly on the tension between the processes of '(re)materialization' and 'dematerialization' (Lucas 2012, p. 213, Fig. 16). Not all the action, however, is wrapped up in this materialization versus dematerialization contest. Two other active forces operate in the complimentary spaces of this framework, although Lucas doesn't expand on them (refer to Fig. 4). These forces, which I call colonization and dissipation, also have vital roles to play within assemblages, principally in reconfiguring or extending them. The contours of colonization are shaped by the dual processes of enchainment/coding and exposure/deterritorialization, the effect of which is to maintain the material coherence of the assemblage while it is displaced, perhaps far away, in time and space from its original setting. Colonization thus radically reconfigures the topology and boundaries of an assemblage. By contrast, the force of dissipation harnesses the twin processes of containment and dispersal to cause elements of an assemblage to break 


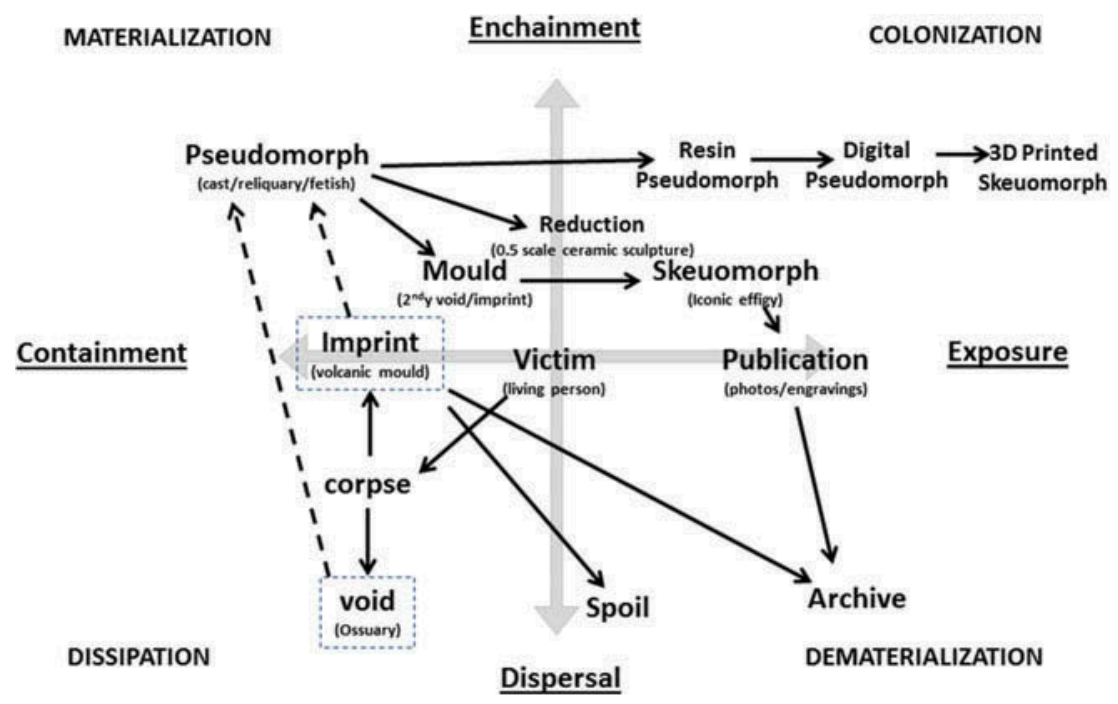

Fig. 4. Mapping the extended Pompeian assemblage due to the fourth pyroclastic surge to the 'enchainment $v$ containment' grid of forces (after Lucas 2012, Fig. 16, p. 213, dissipation and colonization classification labels added).

up and disintegrate in the neighbourhood of their original setting.

Returning to the victims of the fourth surge, we can observe some new aspects of the polyvalent character of this extending assemblage. Immurement ensured that the victims' bodies would remain contained at Pompeii for some considerable time; time enough for dissipation to loosen the corpses from the embrace of their enchained imprints. Once the victims were discovered, however, the dual forces of dematerialization and (re)materialization were actuated simultaneously. The one dismembering the volcanic cocoons as the remains were removed to either spoil heaps or excavation archives, the other precipitating the casts, which were soon beset by the forces of dispersal. The casts started degrading immediately through shrinkage as the plaster dried, by imperfections, such as bubbles and the plugs marking the entrance and egress apertures when the liquid plaster was introduced, and later by the armature of the moulds made to produce the subsequent 'replicas'. These latter are, of course, themselves casts with the same characteristics and limitations (Lazer 2009, p. 254), which in turn amplify the effects of these forces.

Despite this, the trajectory of materialization is sustained by the growing number of reiterations of the victims' bodies, which emphasize the enchainment process by repeated citation of their prototypes. However, while some of the pseudomorphs remained relatively contained at Pompeii (some still in situ), others became peripatetic. Indeed, many skeuomorphs became much more mobile, and mutable, when exposed to the rigours of travel and handling. The gift of the reductions to Kaiser Wilhelm in 1888 is the event that probably marks the genesis of the diaspora of iconic casts - each individual establishing its own, but entwined, biographical thread - spreading around the world and colonizing new assemblages over the following centuries. The potential for a step-order change in colonization occurred in 1994, in Australia, when Lazer and her ensemble of CT scanning technology became entangled with the Lady of Oplontis assemblage. Beside the forensic analysis she produced, 
what also emerged from this encounter was the first digital, or virtual skeuomorph of a Pompeian victim.

\section{VIRTUAL SKEUOMORPHS IN NEW DIGITAL PALIMPSESTS}

What does the curator now have to classify, restitute, conserve, display, copy, or loan? I would argue that the CT scans have recast the victims' traces and residues in a digital recursion which engenders new forms of digital discovery (see Edgeworth 2014), giving them an extended afterlife, generative of multiple new becomings. These virtual casts bring us full circle to the porous cavities, as such digital objects can be very permeable whilst simultaneously immutable.

The boundaries of virtual objects can be ambiguous, and here I'm thinking of 3D printed objects and their definition files (see also Beale and Reilly 2015, pp. 123-125). Tomographic reiteration of the epoxy resin pseudomorph/skeleton enabled a digital skeuomorph to be instantiated in an encoded form. In this new digital form, it became what Bruno Latour calls an 'immutable mobile' (Latour 1987), in that it has some permanence and yet is easily transportable. Digital formats afford further reiterations of the assemblage as physical 3D printed objects (see Nath 2015 for examples of 3D printed 'Pompeii Casts'), a new form of propinquity. Paradoxically, although the additive manufacturing digital code defining the physical things to be $3 \mathrm{D}$ printed is extremely stable, in the sense it doesn't decay, the digital objects thus defined are actually very permeable and extensible. Whereas the limits of the physical objects may be clearly defined surfaces, the boundaries of the digital object are drawn by the same file format in which they are defined; that is, the same digital code that marks the content and the voids. Digital artefacts and assemblages, besides being porous, are easily networked, replicated, aggregated, augmented, resampled, processed, or transcoded into other formats (Berry 2014), and thereby extended. They are also susceptible to new kinds of exploration and analysis. Indeed they can be recontextualized, reiterated, (re)materialized, reconceptualized, re (con)figured, and (re)discovered.

But what can be instantiated from the digital 'record': virtual or physical traces and residues? The answer is both and, as Victor Buchli (2010, pp. 281-282) highlights, conventional understandings of materiality are now problematized, since 'the digital representation and the physical thing are difficult to meaningfully differentiate'. However, although material residues 'remain and last as long as the material of which they are made of lasts' (Olivier 2004, p. 206), these physical objects are subject to decay, damage, and mishandling. Ultimately, and perhaps ironically, it is the 'immaterial digital code' (Buchli 2010, pp. 281-283) and the scans that emerge as the most stable traces between and betwixt virtual and physical worlds.

David Berry, however, rejects the immateriality of code and draws attention to the 'concrete thing-in-this-world-ness of software' (Berry 2011, p. 5). In digital form, both data and code are buried within a new electronic palimpsest under layers of code (e.g. source, executable, machine, operating system), characterized by Jeremy Huggett (2004, p. 84) as 'layers of opacity', and distributed across networks and storage devices, in which they are ultimately inscribed on an inorganic substrate. This technology stack also has a life cycle: code ages and dies; machines break down and become defunct (Berry 2011, pp. 42-51). From this position, both software and data migration, perhaps also some hardware emulation, will likely be required to keep breathing life into these digital objects (for a deeper discussion of the issues of digital preservation see Baker and Anderson 2012, Chue Hong 2012, Mathews et al. 2012). Nevertheless, the key point is that both the scans and the code are what Bernard Stiegler characterizes as 'orthothetic' in nature (Stiegler n.d.). Orthothetic 
here denotes an 'exact' form of recording using digital technologies, such as digital cameras, scanners, storage, and networks, to permit the exact registration, inscription, and repetition of some object or event. Put another way, digital recording technology can capture and put into digital stasis the exact spatial poses of objects, assemblages, or spaces - from one unique fleeting moment of time - and make them available, stabilized exactly as sampled, for all time, when combined with a permanent Internet location (e.g. Digital Object Identifier (DOI)), in principle, to any agent/actant/compactant ${ }^{6}$ with access to an Internet device.

So, while all beings in a flat ontology equally exist, not all the beings are equal and their trajectories are becoming unpredictable. Whereas in the 'old' physical world the processes of materialization and dematerialization were paramount, in the digital universe born-digital instantiations enable more promiscuous translations, and substitutions, to start colonizing adjacent, previously untrammelled, spaces in Lucas' flat ontology. At the same time, formerly irreversible changes are now becoming unstable and indeed reversible as the virtual and material worlds begin to seep, or bleed, into one another.

The concept of territorialization in particular is being challenged in the digital archaeological record. This in and of itself is no bad thing, but it does raise some new, and amplifies many old, issues. For example, if we regard these myriad instantiations to be in some sense human remains, then clearly there are many ethical issues around the display, ownership, handling, treatment, and acceptable use that need to be addressed (e.g. Brooks and Rumsey 2007, Alberti et al. 2009). Of course, many of these ethical issues can be side-stepped by objectifying the casts, replica casts, and reductions and transforming them into artefacts within the global memory market (see Feldman 2006 for a broader discussion of 'lost bodies'). For example, Eugene Dwyer (2005) shows, very clearly, how the body disappears through an objectification discourse when he asks: 'What precisely are the casts are they archaeological artefacts, or are they works of art?' The answer it seems is either one, both, many, more, or less: voids-cumimprints; voids-cum-ossuaries; pseudomorphscum-reliquaries; pseudomorphs-cum-fetishes; skeuomorphs-cum-effigies; bodies-cum-worksof-art; casts-cum-artifacts; casts-cum-ecofact; (im)material-digital-casts-cum-prototypes; 3Dprinted artefacts.

\section{CONCLUSION}

Objects and assemblages gather histories around themselves; they develop cultural biographies as they accumulate new significance, connections, and meaning throughout their existence (Gosden and Marshall 1999). Their meaning and significance, however, is contingent on the web of relations and intraactions in which these entities get caught up in. Meanings, therefore, can be renegotiated, even radically reset. In other words, they are always in progress. As Chris Fowler (2013) shows using the case study of the Kyloe Necklace, the actions, technologies, ideas, and practices we apply in the present extend objects and assemblage in different directions. As the extending, genealogical assemblage of Pompeian victims of the fourth surge continues to branch out, its topology is re (con)figured and multiple new biographical threads of meaning and significance are actuated.

The extending assemblage of the Pompeian victims of the fourth pyroclastic surge of Vesuvius in CE 79 is just one example of a previously (im)material set of entities that is radically destabilizing contemporary understandings of concepts such as real, virtual, original, and authentic.

The eruptions of Vesuvius were not confined to early Roman Imperial Pompeii. The footprints of humans in much earlier Vesuvian ashes, apparently evacuating the area in the Early Bronze Age, testify to this (see Petrone et al. 2014). Vesuvius, of course, 
is not a lonely active volcano. The Minoan Bronze Age town of Akrotiri, on the Aegean island of Santorini (Thera), was also engulfed by volcanic activity. Here, too, archaeologists employ the technique of casting voids to capture the forms of, amongst other things, window frames, furniture, and fishing nets (e.g. Trantalidou 2008, p. 55).

Other examples of significant spaces within material objects are ceramic rattles (e.g. Braun 2002, pp. 100-107, Taxel et al. 2013) and bullae (Marko 2014). Both categories of objects can be characterized as having other objects hidden, sometimes deliberately stashed or sealed, within their physical bodies. Intact bullae are extremely rare, and accessing the interior of such objects is only conceivable using non-invasive techniques (Marko 2014). Here, again, CT scanning and 3D printing enable detailed visual, tactile examination, and previously impossible interventions, such as breaking open the 'new' bulla to investigate its hidden contents, with minimal handling of the original specimen.

Voids have been shown to be ontologically polyvalent, unstable, and subject to repeated transformation due to their contingent and inherently mutable nature. Paradoxically, such instability is simultaneously amplified and arrested in the digital, particularly through the media of additive manufacturing technology, which have the potential to preserve or totally transform future intra-actions with such (im)material assemblages when they are further reiterated, extended, re(con) figured, and deterritorialized, as they are distributed through time and space as 3D printable digital objects.

As evolving technologies continue to blur the ontological boundaries between real and virtual (see Rogers 2009, Carusi 2011, Hoel and van der Tuin 2013), and where 'phenomena are the ontological entanglement of object and the agencies of observation' (Barad 2007, p. 309), categorizations such as copies, clones, facsimiles, imitations, replicas, and reproductions no longer sit comfortably with these objects. Infinitions burst free of such procrustean registers to be (re)printed, endlessly, in different materials, at different scales, with enhanced morphological features, with different (im)material properties, in multiple spatiotemporal locales, to intra-face to, and intra-act with, uncounted new actants.

Currently, digital (im)material entities are emerging as newly deterritorialized and yet-tobe-materialized places or spaces of discovery, where the archaeological assemblage can be condensed into a new prototypical vehicles of archaeological registration, research, conservation, and presentation. In common with other prototypes, these entities can enfold within them various biographical, techno-scientific, and cultural significances as they open up a world of compossibility, facilitating 'a proliferation of abductions and transformations' (Corsin 2014, p. 385), including 3D-printed possibilities the materiality of which is rendered propinquitous (Corsin 2014, p. 382), creating yet more deeply stratified palimpsests of (im)material assemblages in new digital contexts, offering fresh possibilities for further digital acts of discovery and new conceptions of residuality.

\section{ACKNOWLEDGEMENTS}

Figure 1 is reproduced by kind permission of Catriona Cooper. Figure 2 is reproduced by kind permission of WASP. Thanks are also due to Andrew M. Jones, Jude Jones, Yvonne Marshall, Louisa Minkin, and the anonymous reviewers for their helpful comments on an earlier draft of this paper. Residual and subsequent deficiencies remain my own.

\section{NOTES}

${ }^{1}$ I apply the term residue to refer to enduring and ongoing material or physical remains. I use trace in the sense of a persistent mark, or effect, an indication of the existence, or former existence, of something. Traces may be inscribed on a material, but they may also be immaterial. Manifestations include absences, gaps, and discontinuities. Stratigraphic interfaces, 
such as cuts, and the boundaries between overlapping layers are classic examples. In the excavation section drawing, the interface between layers are traced and re-presenced in graphite (whilst, somewhat ironically, the contiguous layers still present are often depicted as blank).

${ }^{2}$ Rather than using the terms 'actor' and 'interactions', I have adopted the neologisms of 'actant' (after Latour 1987) and 'intra-action' (after Barad 2007). Here an actant is any entity (archaeologist, material, object, apparatus, technique, theoretical assumption, method, or force) capable of affecting another entity. Intra-action refers to the mutually constituting, entangled effects of actants connecting, intersecting, or otherwise affecting one another.

${ }^{3}$ Humans were not, of course, the only casualties of this catastrophe. Animals (e.g. dogs, donkeys, and pigs) and plants (e.g. trees), plus other organic residues, including 'lost' wooden doors, shutters, even loafs of bread, are known to have been recorded at Pompeii using such casting techniques (Dwyer 2011, pp. 46, 55). 'The Dog from Pompeii August 24, 79 A.D.', 1991, by artist Allan McCollum, is probably the most famous cast (McCollum n.d.).

${ }^{4}$ I use '(im)material' throughout to indicate a pairing or the coexistence of both physical material elements and non-physical immaterial elements, most notably to indicate the imprint and void entanglements.

${ }^{5}$ Giorgio Agamben (1999), Sven Ouzman (2006), Bruno Latour and Adam Lowe (2011), and, more recently, Stuart Jeffrey (2015), invoking widely divergent examples, argue that aura can indeed be reconstituted anew in different rematerializations of an object, including digital instantiations (Jeffrey 2015).

${ }^{6 .}$ Compactants, or computational actants, are mediation processes and interfaces/intrafaces between intra-acting devices, code, and data structures and networks (Berry 2014, pp. 68-69).

\section{REFERENCES}

Agamben, G., 1999. The man with bo content. Stanford, CA: Stanford University Press.

Alberti, S., Bienkowski, P., Chapman, M., and Drew, R., 2009. Should we display the dead? Museum and Society, 7, 133-149.
Baker, D., and Anderson, D., 2012. Laying a trail of breadcrumbs - preparing the path for preservation. In: J. Delve, D. Anderson, M. Dobreva, D. Baker, C. Billenness, and L. Konstantelos, eds. The preservation of complex objects: volume 1. Visualisations and simulations. Portsmouth: University of Portsmouth, 15-23.

Barad, K., 2007. Meeting the universe halfway: quantum physics and the entanglement of matter and meaning. Durham, NC: Duke University Press.

Barad, K., 2010. Quantum entanglements and the hauntological relations of inheritance: dis/ continuities, SpaceTime enfoldings, and justice-tocome. Derrida Today, 3 (2), 240-268.

Beale, G., and Reilly, P., 2015. Additive archaeology: the spirit of virtual archaeology reprinted. In: C. Papadopoulos, E. Paliou, A. Chrysanthi, E. Kotoula, and A. Sarris, eds. Archaeological research in the digital age. Proceedings of the 1st conference on computer applications and quantitative methods in archaeology Greek chapter (CAA-GR), 6-8 March 2014 Rethymno, Crete. Rethymno: Institute for Mediterranean Studies Foundation of Research and Technology (IMS-Forth), 120-128.

Berry D.M., 2011. The philosophy of software: code and mediation in the digital age. Basingstoke: Palgrave Macmillan.

Berry D.M., 2014. Critical theory and the digital. London: Bloomsbury Academic.

Braun, J., 2002. Music in ancient Israel/Palestine: archaeological, written, and comparative sources. Cambridge: Wm. B. Eerdmans Publishing

Brooks, M.M., and Rumsey, C., 2007. Who knows the fate of his bones? Rethinking the body on display: object, art or human remains? In: J. Knell, S. Macleod, and S. Watson, eds. Museum revolutions: how museums change and are changed. London: Routledge, 334-354.

Buchli, V., 2010. The prototype: presencing the immaterial. Journal of Visual Communications, 9, 273-286.

Carusi, A., 2011. Trust in the virtual/physical interworld. In: C. Ess and M. Thorseth, eds. Trust and virtual worlds: contemporary perspectives. New York: Peter Lang, 103-119.

Chue Hong, N., 2012. Digital preservation and curation: the danger of overlooking software preservation. In: J. Delve, D. Anderson, M. Dobreva, D. Baker, C. Billenness, and L. 
Konstantelos, eds. The preservation of complex objects: volume 1. Visualisations and simulations. Portsmouth: University of Portsmouth, 25-35.

Corsin Jimenez, A., 2014. Introduction. Journal of Cultural Economy, 7 (4), 381-398.

Domanska, E., 2005. Towards the archaeontology of the dead body. Rethinking History: The Journal of Theory and Practice, 9, 389-413.

Dwyer, E., 2005. From fragments to icons: stages in the making and exhibiting of the casts of Pompeian victims, 1863-1888 [online]. Interpreting Ceramics, 8. Available from: http://www.interpretingceramics.com/issue008/ articles/06.htm [Accessed 18 January 2015].

Dwyer, E., 2010. Pompeii's living statues: ancient Roman lives stolen from death. Ann Arbor: University of Michigan Press.

Dwyer, E., 2011. The first plaster casts of the Pompeian victims. In: P. Bonaventura and A. Jones, eds. Sculpture and archaeology. Farnham: Ashgate Publishing, 45-60.

Edgeworth, M., 2003. Acts of discovery: an ethnography of archaeological practice. BAR International Series 1131. Oxford: Archaeopress.

Edgeworth, M., 2014. From spade-work to screenwork: new forms of archaeological discovery in digital space. In: A. Carusi, A.S. Hoel, T. Webmoor, and S. Woolgar, eds. Visualization in the age of computerization. Abingdon: Routledge, 40-58.

Feldman, J.D., 2006. Contact points: museums and the lost body problem. In: E. Edwards, C. Gosden, and R.B. Phillips, eds. Sensible objects: colonialism, museums and material culture. Oxford: Berg, 245-268.

Fowler, C., 2013. Dynamic assemblages, or the past is what endures: change and the duration of relations. In: B. Alberti, A.M. Jones, and J. Pollard, eds. Archaeology after interpretation: returning materials to archaeological theory. Walnut Creek: Left Coast Press, 235-256.

Fowles, S., 2010. People without things. In: M. Bille, F. Hastrup, and T.F. Sorensen, eds. An anthropology of absence. Materialializations of transcendence and loss. New York: Springer, 23-41.

Gosden, C., and Marshall, Y., 1999. The cultural biography of objects. World Archaeology, 31 (2), 169-178.

Horada, S., 2014. The void: an archaeological survey [online]. Available from: http://www. kamellazaarfoundation.org/initiatives/4/39 [Accessed 30 November 2014].

Hoel, A.S., and van der Tuin, I., 2013. The ontological force of technicity: reading Cassirer and Simondon diffractively. Philosophy and Technology, 26 (2), 187-202.

Huggett, J., 2004. Archaeology and the new technological fetishism. Archeologia e Calcolatori, $15,81-92$.

Ingold, T., 2007. Materials against materiality. Archaeological Dialogues, 14, 1-16.

Jeffrey, S., 2015. Challenging heritage visualisation: beauty, aura and democratisation. Open Archaeology, 1 (1), 144-152.

Latour, B., 1987. Science in action: how to follow scientists and engineers through society. Cambridge, MA: Harvard University Press.

Latour, B., and Lowe, A., 2011. The migration of aura or how to explore the original through its facsimiles. In: T. Bartscherer and R. Coover, eds. Switching codes: thinking through digital technology in the humanities and the arts. Chicago, IL: Chicado University Press, 275-298.

Lazer, E., 2009. Pompeii resurrected. London: Routledge.

Lobell, J.A., 2011. Pompeii's dead reimagined [online]. Archaeology - Archive, 64 (5). Available from: http://archive.archaeology.org/ 1109/features/pompeii_casts_gary_staab.html [Accessed 12 July 2015].

Lucas, G., 2012. Understanding the archaeological record. Cambridge: Cambridge University Press.

Marko, A., 2014. The modern ancient tablet: a curatorial intervention [online]. Available from: http://curatorialpracticum.wordpress.com/2014/ 05/04/the-modern-ancient-tablet/ [Accessed 15 July 2015].

Marshall. Y., and Alberti, B., 2014. A matter of difference: Karen Barad, ontology and archaeological bodies. Cambridge Journal of Archaeology, 24 (1), 19-36.

Mastrolorenzo, G., Petrone, P., Pappalardo, L., and Guarino, F.M., 2010. Lethal thermal impact at periphery of pyroclastic surges: evidences at Pompeii. PLoS ONE, 5 (6), e11127.

Mathews, B., Shaon, A., and Conway, E., 2012. How do I know that I have preserved software? In: J. Delve, D. Anderson, M. Dobreva, D. Baker, C. Billenness, and L. Konstantelos, eds. The preservation of complex objects: volume 1 . Visualisations and simulations. Portsmouth: University of Portsmouth, 36-53. 
McCollum, A., n.d. The dog from pompeii august 24, 79 A. D. [online]. Available from: http:// allanmccollum.net/amcnet2/album/pompeidog. html [Accessed 21 February 2015].

Morton, T., 2013. Hyperobjects: philosophy and ecology after the end of the world. London: University of Minnesota Press.

Nath, R., 2015. Initiative taken to restore 'Pompeii casts' using 3D printing technology [online]. think3D. Available from: http://www.think3d.in/ initiative-taken-to-restore-pompeii-casts-using3d-printing-technology/ [Accessed 25 July 2015].

Olivier, L., 2004. The past of the present: archaeological memory and time. Archaeological Dialogues, 10, 204-213.

Ouzman, S., 2006. The beauty of letting go: fragmenting museums and archaeologies of archive. In: E. Edwards, C. Gosden, and R.B. Phillips, eds. Sensible objects: colonialism, museums and material culture. Oxford: Berg, 269-301.

Petrone, P., Niola, M., di Lorenzo, P., Graziano, V., Paternoster, M., and Buccelli, C., 2014. A new forensic approach to past mass disasters: the human victims of Vesuvius. Austin Journal of Forensic Science and Criminology, 1 (1), 2.
Roberts, P., 2013. Life and death in Pompeii and Herculaneum. London: British Museum Press.

Rogers, R., 2009. The end of the virtual: digital methods. Amsterdam: Vossiuspers.

Shanks, M., 1992. Experiencing archaeology. London: Routledge.

Stiegler, B., n.d. Ananmnesis and Hypomnesis [online]. Available from: http://arsindustrialis. org/anamnesis-and-hypomnesis [Accessed 15 July 2015].

Taxel I., Iserlis, M., and Yannai, E., 2013. The inside out of childhood archaeology: petrographic and X-ray analysis of early Islamic ceramic rattles from Mishmar David (Israel) and their cultural implications. Journal of Eastern Mediterranean Archaeology and Heritage Studies, 3 (1), 219-227.

Trantalidou, K., 2008. Archaeozoological research at the Akrotiri excavation. $A \Lambda \Sigma$ (Periodical Publication of the Society for the Promotion of Studies on Prehistoric Thera), 6, 26-69.

Whitehead, A.N., 1929. Process and reality: an essay on cosmology. Cambridge: Cambridge University Press. 